Document downloaded from:

http://hdl.handle.net/10251/52289

This paper must be cited as:

Silveira Thiago Rosa, CD.; Melges, J.; Paya Bernabeu, JJ.; Akasaki, JL.; Marinho, J.; Oliveira, D. (2014). Characterization of ash sludge from wastewater treatment plants: Assessment for construction purposes. Key Engineering Materials. 600:628-637. doi:10.4028/www.scientific.net/KEM.600.628.

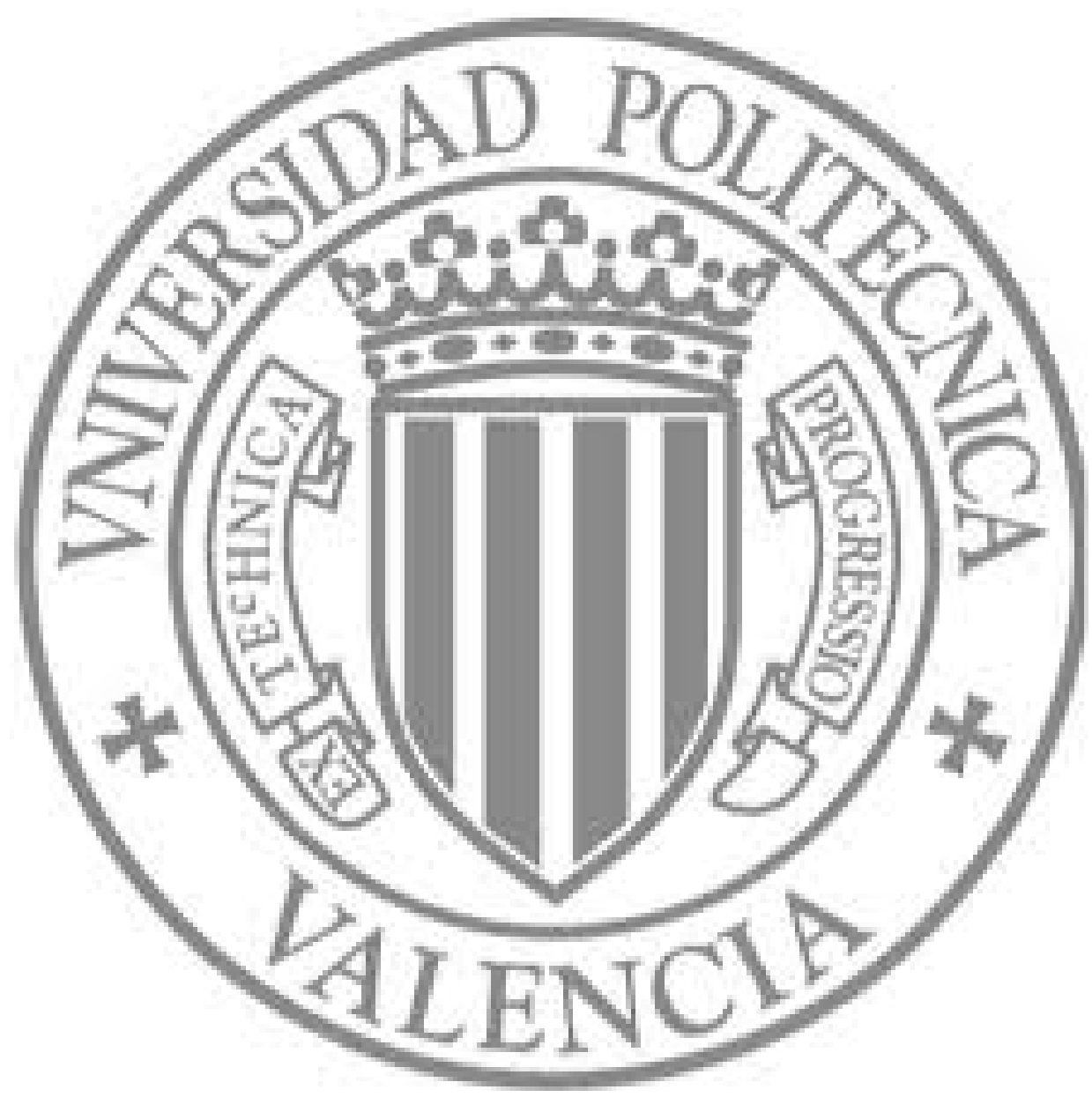

The final publication is available at

http://dx.doi.org/10.4028/www.scientific.net/KEM.600.628

Copyright Trans Tech Publications 


\title{
Characterization of Ash Sludge from Wastewater Treatment Plants: Assessment for Construction Purposes
}

\author{
Cristiane Maria da Silveira Thiago Rosa ${ }^{1, \text { a }}$, José Luiz Pinheiro Melges ${ }^{2, b}$, \\ Jordi Payá ${ }^{3, c}$, Jorge Luís Akasaki ${ }^{4, d}$, Jean Richard Dasnoy Marinho ${ }^{5, \mathrm{e}}$ and \\ Douglas Santos Oliveira ${ }^{6, f}$
}

\author{
1, 2, 4, 5, 6 UNESP - Univ. Estadual Paulista, Ilha Solteira, Alameda Bahia, 550, Ilha Solteira - SP \\ 15.385-000, Brazil \\ ${ }^{3}$ Instituto de Ciencia y Tecnología del Hormigón - ICITECH, Universitat Politècnica de València, \\ Camino de Vera s/n, 46071, Valencia, Spain \\ acristiane-thiago@hotmail.com, ${ }^{\mathrm{b}}$ ilmelges@dec.feis.unesp.br, ${ }^{\circ}$ ijpaya@cst.upv.es, \\ d akasaki@dec.feis.unesp.br, ${ }^{\mathrm{e}}$ iean@dfq.feis.unesp.br, ${ }^{\dagger}$ douglasso393@gmail.com
}

Keywords: sewage sludge, ash, chemical property, alternative material, construction.

\begin{abstract}
Considering that the human being is in a universe where the population demand for consumer goods is rapidly growing, the United Nations (UN) concluded that the effective implementation of the use of renewable resources has a nearing deadline. As a result of population growth, a massive waste is generated, especially sewage, requiring adjustments in its disposal, treatment and final disposal. Based on this information, it must be highlighted that the generation of municipal waste due to the sewer, with a significant production of biogas and of sludge, presents major environmental problem due to their volume, size and features. This work points out that the ash of the wastewater sludge can have a more productive destination if used as an alternative material of construction. The research was divided into three stages. In the first stage, it was sample preparation sludge performed; in the second one, burning procedures were designed, and, in the third one, physical-chemical and mineralogical tests for the sewage sludge ash were made, seeking to assess the feasibility of using this residue in mortar and in concrete. According to the conducted studies, it was observed that there is a potential pozzolanic reactivity when using this material as a mineral admixture for Portland cement replacement.
\end{abstract}

\section{Introduction}

The sanitary treatment system based on the activated sludge technique is widely used worldwide. It basically consists in the separation of the solid part of the sewage through a process of dehydration by centrifugation. In this process, secondary phase sewage is sent to an UASB (Upflow Anaerobic Sludge Blanket), where it undergoes anaerobic digestion, generating methane gas and anaerobic sludge. Then, the sludge is sent to centrifuges and later released in buckets directly to the landfill, worrying environmentalists due to a large volume of residue that is generated. Actually many papers points out that the ash of the wastewater sludge may have a more productive destination if used as an alternative material of construction.

The Sewage Treatment Station (SEMAE), located in São José do Rio Preto city, uses the UASB system. At this Station, there is a rigid control of temperature and $\mathrm{pH}$, to maintain the efficiency of the microorganisms used to digest organic matter; the characterization of the biogas that is generated is also done. This control is done by means of experimental tests in its own laboratory. 


\section{Revision of literature}

The ashes of urban sewage sludge are not spherical, being irregular when compared to ordinary cement. This fact provokes a negative effect on workability and consistency. Nevertheless, the ash behaves as an active material causing an increase in compressive strength as compared to the control, due to their pozzolanic properties [1]. Experimental results showed that the ash of sludge can be used as an addition to concrete, with a predominant effect of filler, in percentages of up to $20 \%$ in concrete with a water/binder ratio between 0.65 and 1.10 ; a reduction of the consumption of cement and improved mechanical properties of the concrete were also observed [2]. The fineness of the ashes of sanitary sludge can significantly influence some of the properties of mortars. Through mechanical grinding of the ash, whose fineness was increased, and with the partial substitution of Portland cement for this material, were noted an improvement in workability and consistency and a greater compression strength [3].

Considering the possibility of the corrosion of the reinforcement, it is possible to incorporate the ash of sewage sludge since this procedure may reduce the content of salts, without a significant loss of strength [4].

The incorporation of sewage sludge ash and municipal solid waste in mortars and high performance concrete can provide better physical-mechanical performance and durability. These materials performed quite well in respect to immobilization of heavy metals within the cement matrix. Due to the particle size and to the amorphous content, it was observed a high pozzolanic activity, contributing to the satisfactory performance of the high performance concrete [5].

Through a scanning electron microscopy, it was observed, in cement pastes with 30\% replacement of cement by ash sludge, the formation of ettringite [6] due to the presence of sulphates in this residue.

\section{Experimental}

The research was divided into four stages. In the first stage, the samples were collected and transported from São José do Rio Preto city to Ilha Solteira city, both in Sao Paulo State (Brazil). In the second, it was performed sample preparation sludge; in the third one, burning procedures were designed, and, in the fourth one, physical-chemical and mineralogical tests for the Sewage Sludge Ash were made, named from this point as SSA, seeking to assess the feasibility of using this residue in mortar and concrete.

Sample Collect Procedure. The samples were collected and transported from the SEMAE, at São José do Rio Preto city, to the UNESP - Univ Estadual Paulista, at Ilha Solteira city, by means of styrofoam boxes, with ice, in order to keep the material properties.

Preparation of samples. In order to evaluate the loss of free water in the sample during the preparation process of the sewage sludge ash (SSA), the samples were weighed and dried at a temperature of $100^{\circ} \mathrm{C}$ for $24 \mathrm{~h}$ in an oven-dry, at UNESP (Fig. 1).

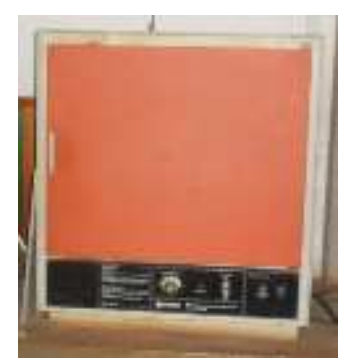

a) Oven-dry

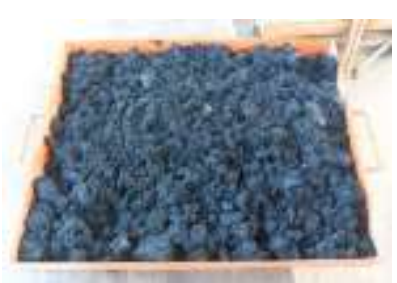

b) Moistured material

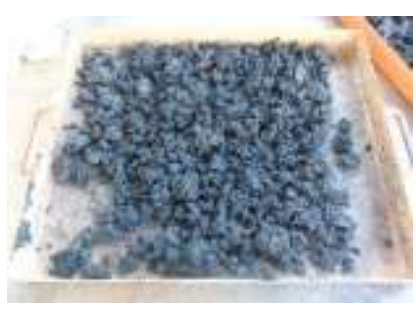

c) Dried material

Fig. 1: Preparation of the material. 
Subsequently, the dried sludge was grounded using a rotating mill with steel balls for a period of 40 minutes, at the Laboratory CESP of Civil Engineering, at Ilha Solteira city. Thus, a fine grained material was obtained, with $100 \%$ passing through ABNT 30 sieve $(0.056 \mathrm{~mm})$, used as reference in this study (Fig. 2).
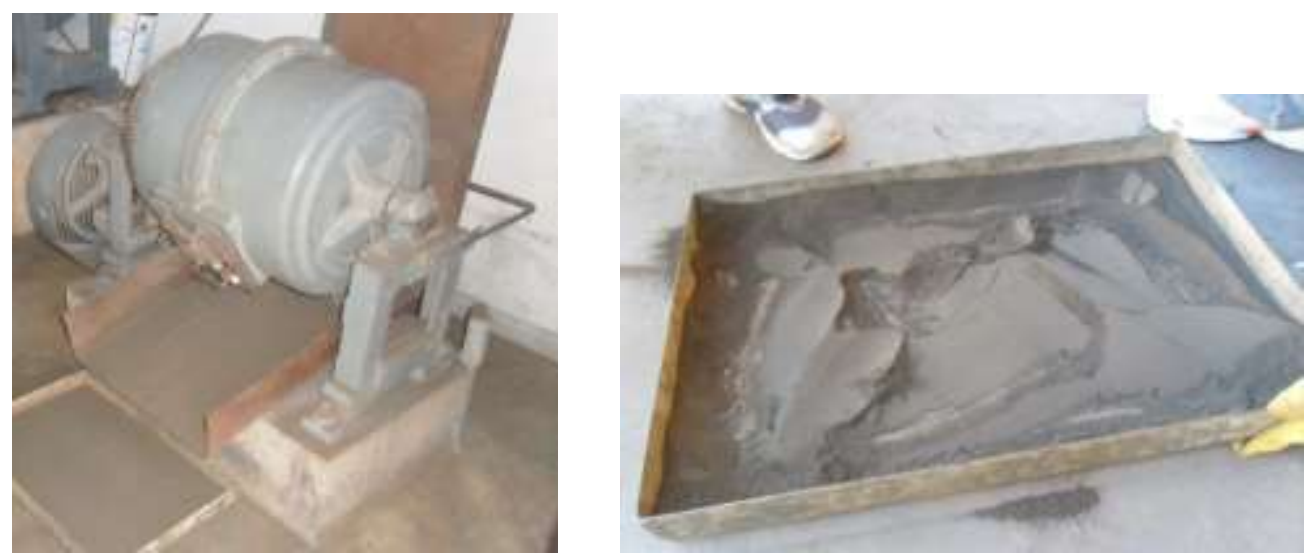

Fig. 2: Steel balls mill and fine grained material.

Burning Procedures. The dry sludge was calcined in a furnace at UNESP - Univ Estadual Paulista. In order to make a comparison, different firing temperatures were set. They were $550^{\circ} \mathrm{C}$, $650^{\circ} \mathrm{C}, 750^{\circ} \mathrm{C}$ and $850^{\circ} \mathrm{C}$ (Fig. 3). For all the fixed temperatures, the period of firing was 4 hours. The loss of material is attributed to elimination of the organic matter present in the dried sludge.
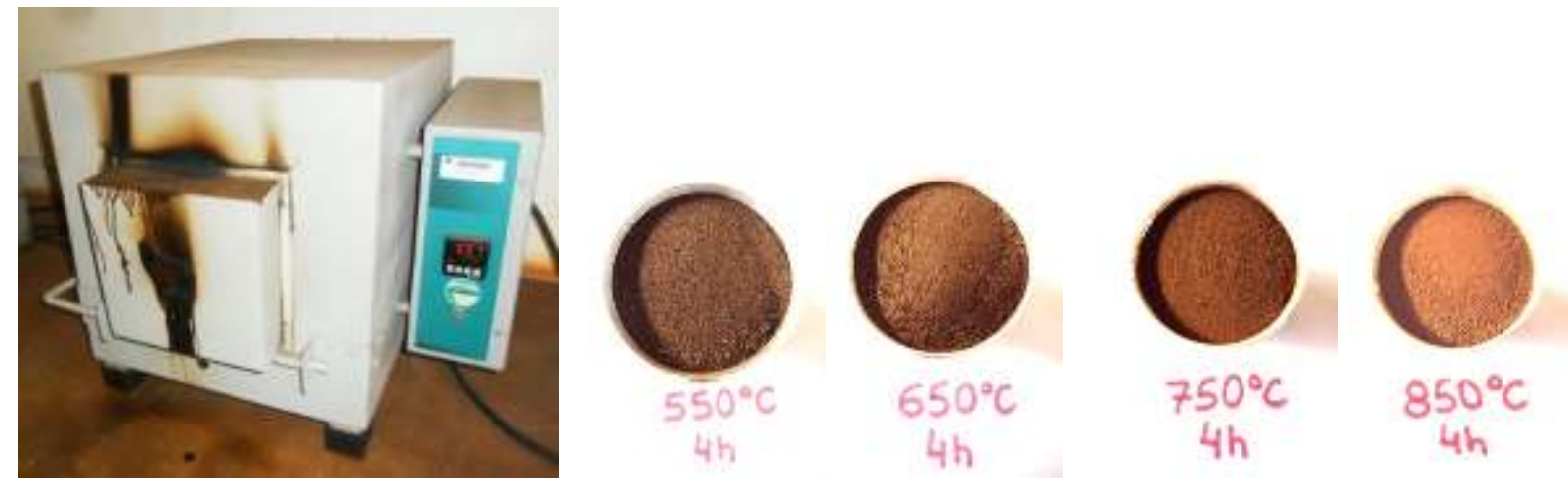

Fig. 3: Furnace and the obtained samples for a firing period equal to 4 hours.

Physical-chemical Tests. After the samples have been calcined, specific physical-chemical analysis were performed to identify the majority elements contained in the sludge.

The EDX analysis showed the presence of several components which allowed identify the amount of oxides present in the sample. This test was done in the Institute of Chemistry of Sao Carlos, University of São Paulo (USP).

X-Ray Diffraction tests were also done in order to obtain their mineralogical compositions (Fig. 4). This test was done at UNESP - Univ Estadual Paulista.

Chloride content in ashes was determined by means of titration with silver nitrate. One gramme $(1 \mathrm{~g})$ of sample was suspended in boiling deionized water for 1 hour. The suspension was filtered and then washed with hot water. The liquid phase was titrated using 0.1M AgNO3 solution (Fig. 5). This test was made at the Instituto de Ciencia y Tecnología del Hormigón (ICITECH), Universitat Politècnica de València. 
Pastes obtained by mixing commercial Brazilian hydrated lime, ashes and water in 3/7/7 ratio were prepared. These pastes were cured at room temperature $\left(25^{\circ} \mathrm{C}\right)$ for 3 months. Dried samples were studied by means of thermogravimetric analysis (TG), at the ICITECH, as shown in Fig. 6.
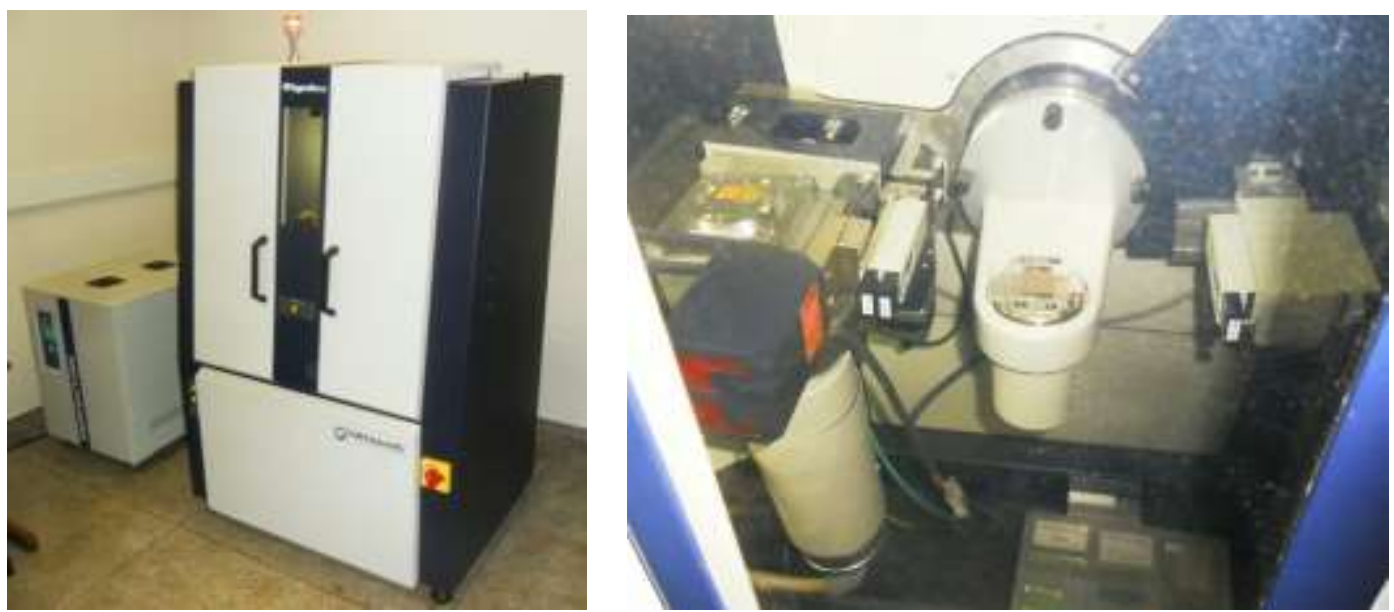

Fig. 4: Equipment used for the Diffraction of x-rays test.
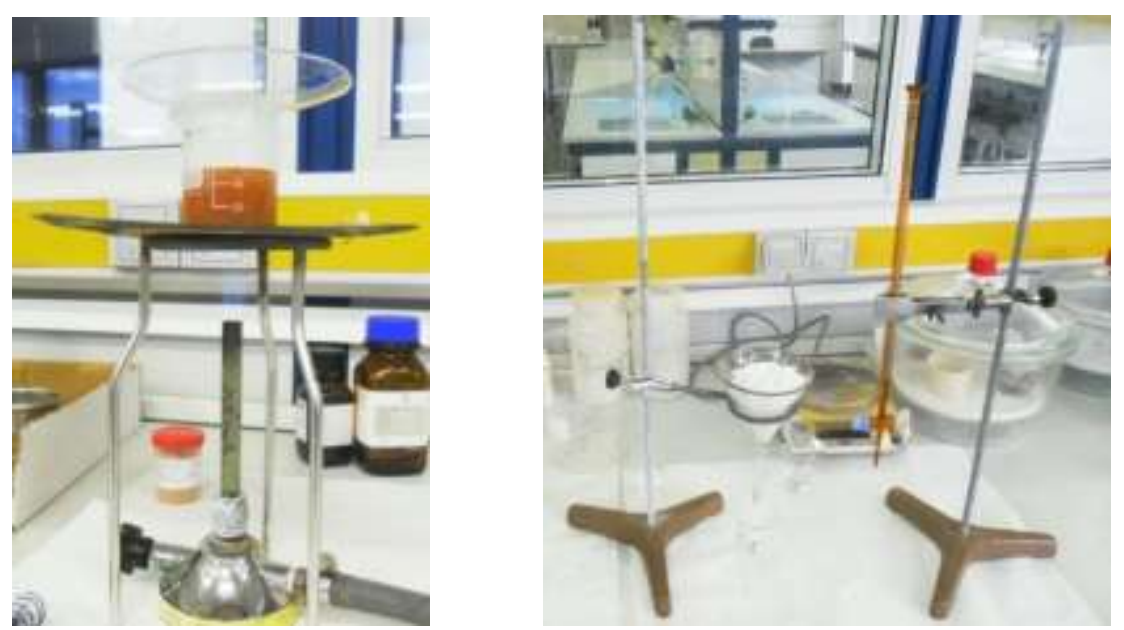

Fig. 5: Equipment used to determine the content of chloride in the ash sample.

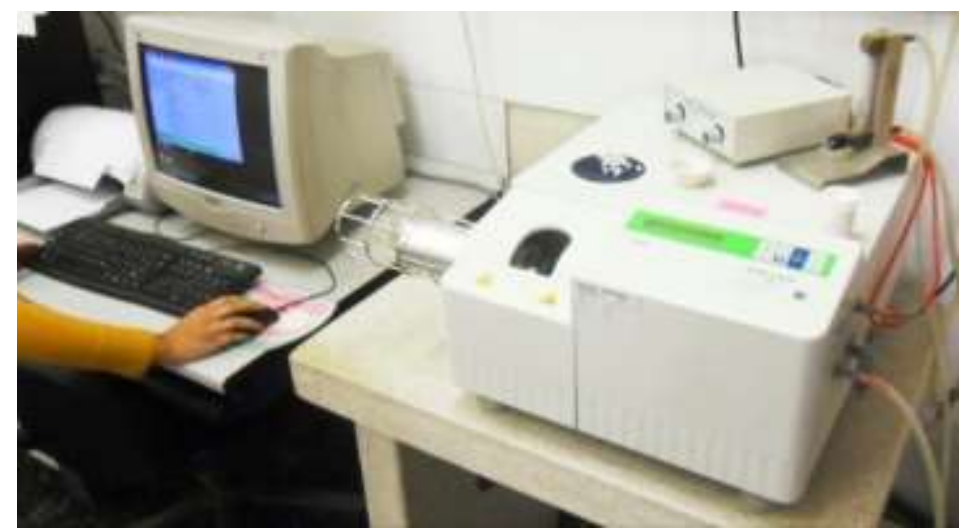

Fig. 6: Equipment used to make the thermogravimetric analysis (TG). 


\section{Results and Discussion}

The loss of mass of sludge, in nature, due to the elimination of free water by the oven-dry was equal to $77 \%$. Furthermore, the losses due to the calcination for different temperatures are shown in Table 1 , being observed values in a range of $54 \%$ to $58 \%$.

Table 2 shows the chemical elements identified in the EDX test.

The proportions of chemical elements, excluding only the element oxygen so as not to distort the scale and facilitate the visualization of other chemical elements, are represented in Fig. 7.

Table 3 shows the percentage of the oxides.

Table 1: Loss of mass due to the calcination procedure (period of 4 hours)

\begin{tabular}{|c|c|c|c|c|}
\hline Sample & Temperature $\left[{ }^{\circ} \mathrm{C}\right]$ & Initial mass $[\mathrm{g}]$ & Final mass $[\mathrm{g}]$ & Loss of mass [\%] \\
\hline 1 & $550^{\circ} \mathrm{C}$ & 300.18 & 138.17 & $54 \%$ \\
\hline 2 & $650^{\circ} \mathrm{C}$ & 300.10 & 126.80 & $58 \%$ \\
\hline 3 & $750^{\circ} \mathrm{C}$ & 300.24 & 128.47 & $57 \%$ \\
\hline 4 & $850^{\circ} \mathrm{C}$ & 300.18 & 125.57 & $58 \%$ \\
\hline
\end{tabular}

Table 2: Chemical element composition for samples after 4 hours of calcination, at different temperatures

\begin{tabular}{|c|c|c|c|c|c|c|c|c|}
\hline \multirow{2}{*}{ Element } & \multicolumn{4}{|c|}{ Mass percentage [\%] } & \multicolumn{3}{c|}{ Atomic percentage [\%] } \\
\cline { 2 - 9 } & $550^{\circ} \mathrm{C}$ & $650^{\circ} \mathrm{C}$ & $750^{\circ} \mathrm{C}$ & $850^{\circ} \mathrm{C}$ & $550^{\circ} \mathrm{C}$ & $650^{\circ} \mathrm{C}$ & $750^{\circ} \mathrm{C}$ & $850^{\circ} \mathrm{C}$ \\
\hline $\mathrm{C}$ & 15.32 & 14.37 & 13.70 & 12.38 & 23.54 & 22.16 & 21.07 & 19.46 \\
\hline $\mathrm{O}$ & 48.92 & 49.25 & 50.59 & 49.22 & 56.43 & 57.04 & 48.38 & 58.08 \\
\hline $\mathrm{Na}$ & 0.37 & 0.37 & 0.37 & 0.36 & 0.29 & 0.30 & 0.29 & 0.29 \\
\hline $\mathrm{Mg}$ & 0.66 & 0.52 & 0.67 & 0.68 & 0.50 & 0.40 & 0.51 & 0.53 \\
\hline $\mathrm{A} \ell$ & 7.51 & 8.48 & 8.16 & 8.66 & 5.14 & 5.82 & 5.59 & 6.06 \\
\hline $\mathrm{Si}$ & 10.79 & 11.97 & 12.34 & 13.19 & 7.09 & 7.90 & 8.11 & 8.87 \\
\hline $\mathrm{P}$ & 1.81 & 1.66 & 1.92 & 2.19 & 1.08 & 0.99 & 1.15 & 1.34 \\
\hline $\mathrm{S}$ & 2.35 & 1.73 & 1.43 & 1.02 & 1.35 & 1.00 & 0.82 & 0.60 \\
\hline $\mathrm{K}$ & 0.43 & 0.49 & 0.44 & 0.57 & 0.20 & 0.23 & 0.21 & 0.27 \\
\hline $\mathrm{Ca}$ & 3.01 & 2.92 & 2.83 & 3.33 & 1.38 & 1.35 & 1.31 & 1.57 \\
\hline $\mathrm{Ti}$ & 1.25 & 1.37 & 1.40 & 1.70 & 0.48 & 0.53 & 0.54 & 0.67 \\
\hline $\mathrm{Fe}$ & 7.58 & 6.88 & 6.14 & 6.71 & 2.50 & 2.28 & 2.03 & 2.27 \\
\hline $\mathrm{Total}$ & 100.00 & 100.00 & 100.00 & 100.00 & 100.00 & 100.00 & 100.00 & 100.00 \\
\hline
\end{tabular}

Table 3: Percentage of oxides, calculated from the chemical elements identified in the EDX test, for each temperature of calcination

\begin{tabular}{|c|c|c|c|c|c|c|c|c|c|c|}
\hline \multirow{2}{*}{$\begin{array}{c}\text { Tempe- } \\
\text { rature }\end{array}$} & \multicolumn{10}{|c|}{ Percentage of oxides [\%] } \\
\cline { 2 - 14 } & $\mathrm{MgO}$ & $\mathrm{Al}_{2} \mathrm{O}_{3}$ & $\mathrm{SiO}_{2}$ & $\mathrm{P}_{2} \mathrm{O}_{5}$ & $\mathrm{SO}_{3}$ & $\mathrm{~K}_{2} \mathrm{O}$ & $\mathrm{CaO}$ & $\mathrm{TiO}_{2}$ & $\mathrm{Fe}_{2} \mathrm{O}_{3}$ & Total \\
\hline $550^{\circ} \mathrm{C}$ & 1.16 & 30.43 & 24.69 & 8.90 & 6.27 & 1.09 & 4.49 & 2.06 & 20.90 & 100.00 \\
\hline $650^{\circ} \mathrm{C}$ & 0.90 & 33.56 & 26.80 & 7.95 & 4.52 & 1.22 & 4.27 & 2.22 & 18.56 & 100.00 \\
\hline $750^{\circ} \mathrm{C}$ & 1.18 & 32.93 & 28.10 & 9.43 & 3.79 & 1.14 & 4.24 & 2.31 & 16.88 & 100.00 \\
\hline $850^{\circ} \mathrm{C}$ & 1.22 & 34.66 & 29.10 & 10.25 & 2.61 & 1.38 & 4.73 & 2.87 & 17.17 & 100.00 \\
\hline
\end{tabular}




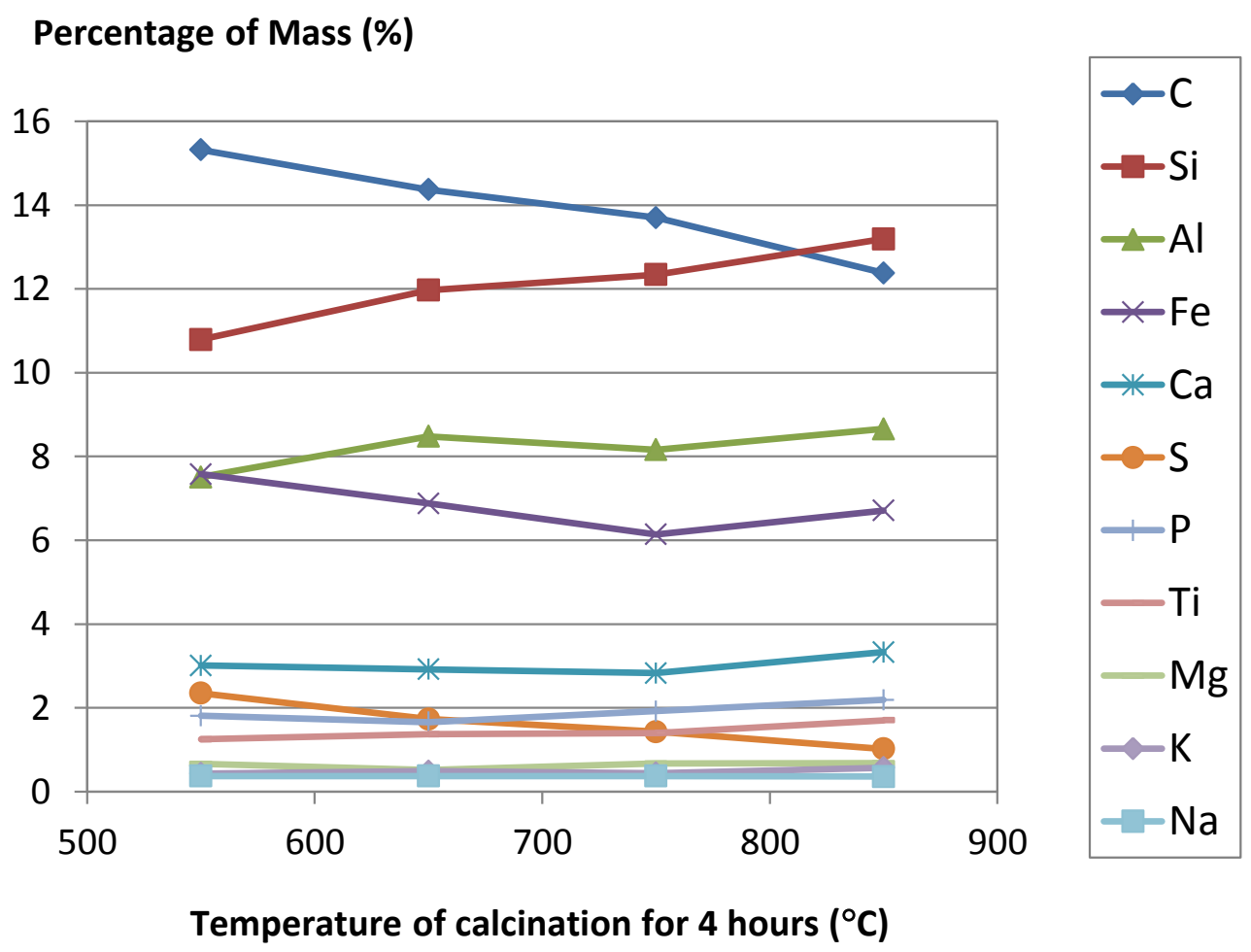

Fig. 7: Percentage of mass for the identified chemical elements (except oxygen).

The results related only to some selected oxides of the material, for different temperatures of calcination, are presented in Fig. 8.

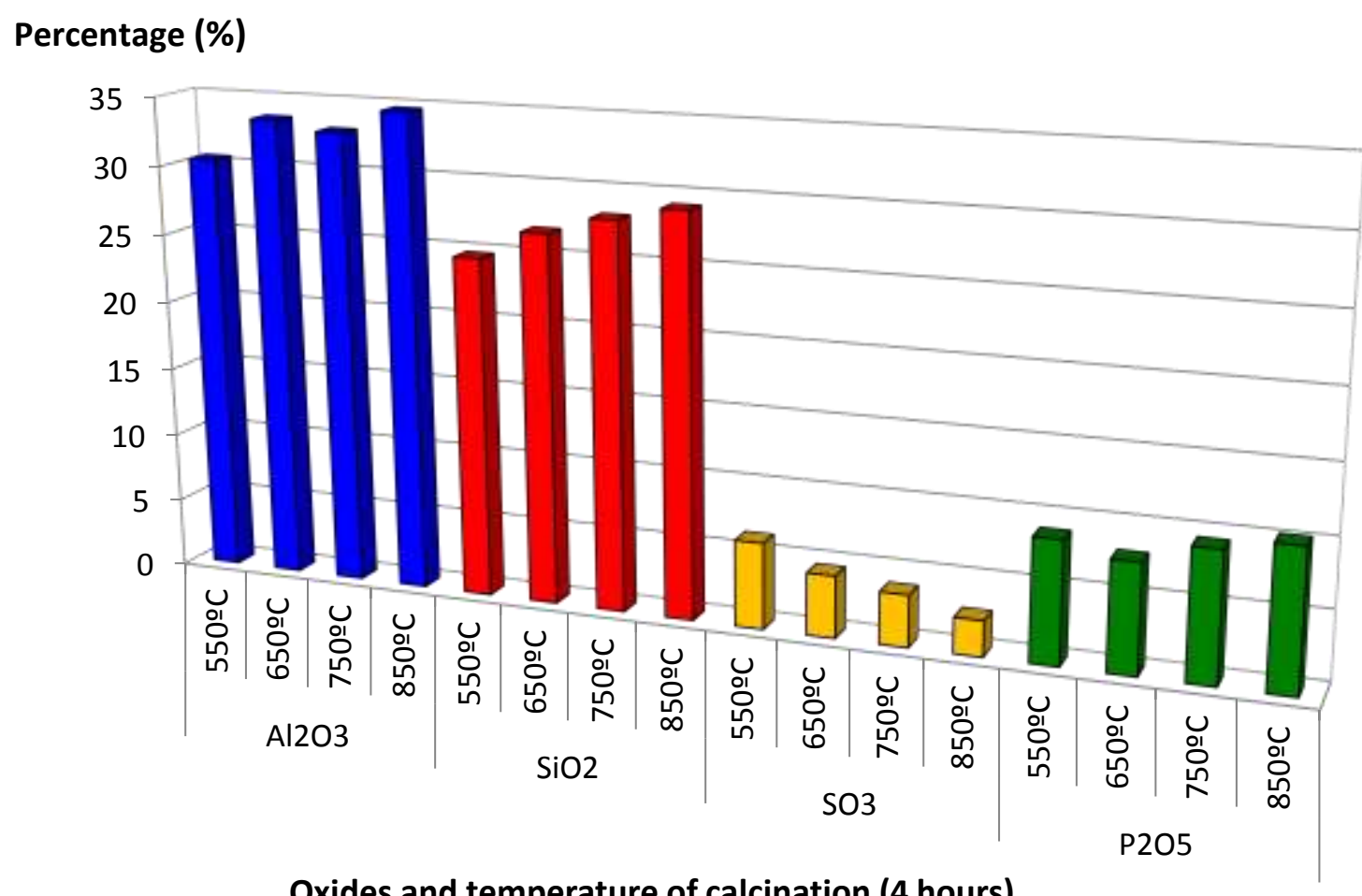

Oxides and temperature of calcination (4 hours)

Fig. 8: Percentage of some selected oxides of the ashes. 
The result of the test of X-Ray Diffraction, for two samples, at the temperatures of $650^{\circ} \mathrm{C}$ and $850^{\circ} \mathrm{C}$, is shown in Fig. 9.

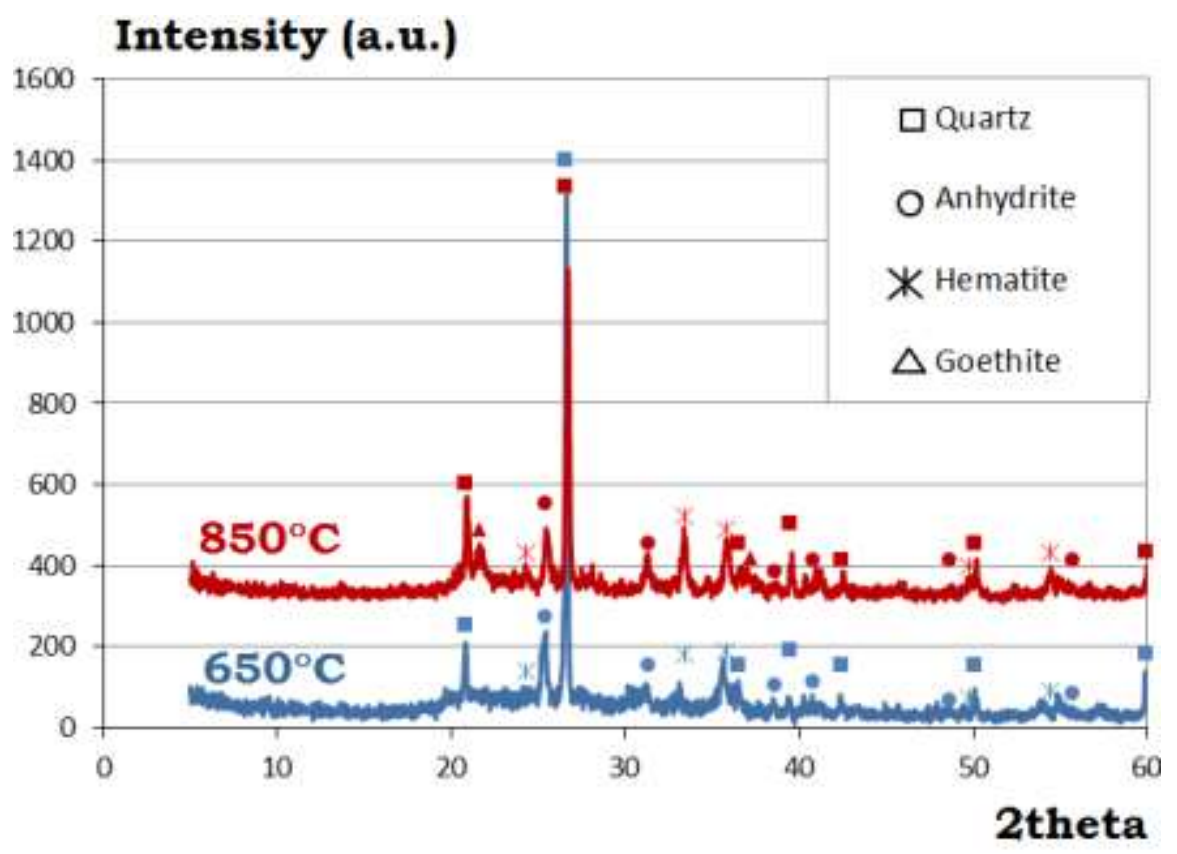

Fig. 9: X-Ray Diffraction test for samples calcinated at temperatures of $650^{\circ} \mathrm{C}$ and $850^{\circ} \mathrm{C}$.

The results of TG and DTG tests for hydrated lime pastes prepared by mixing with SSA calcinated at temperatures of $650^{\circ} \mathrm{C}$ and $850^{\circ} \mathrm{C}$ are shown in Fig. 10 and Fig. 11, respectively.

Table 4 shows the values of the temperatures corresponding to the peaks observed in Fig. 11.

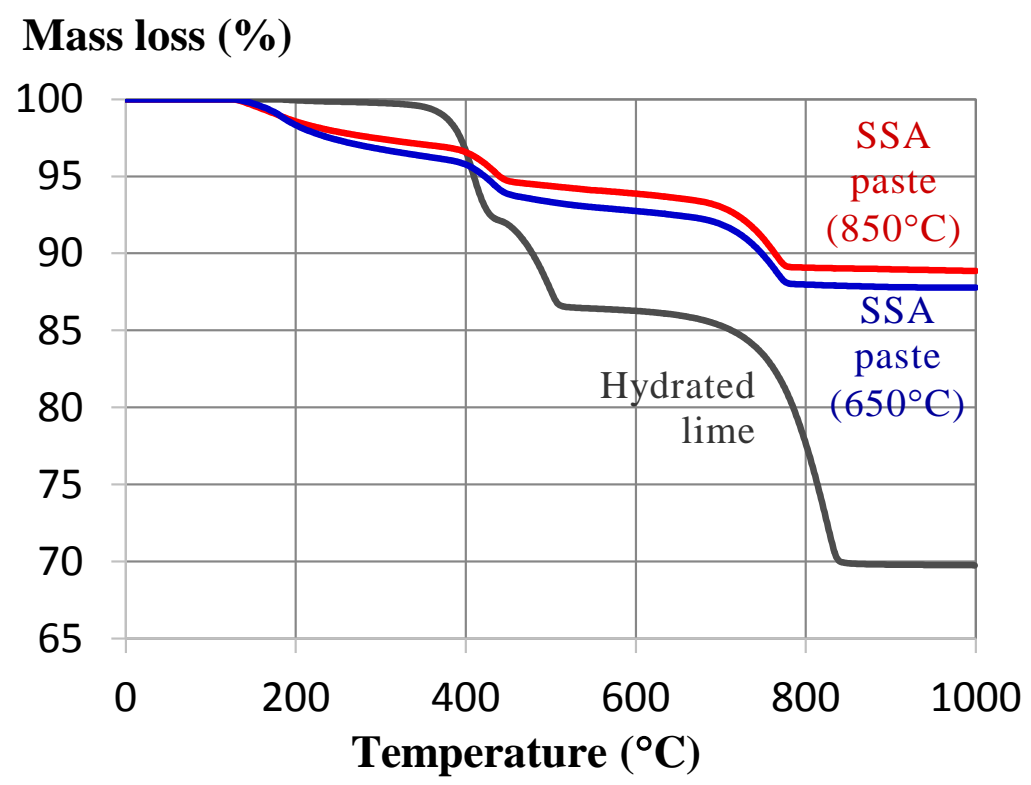

Fig. 10: TG curves for hydrated lime / SSA calcinated at temperatures of $650^{\circ} \mathrm{C}$ and $850^{\circ} \mathrm{C}$. 


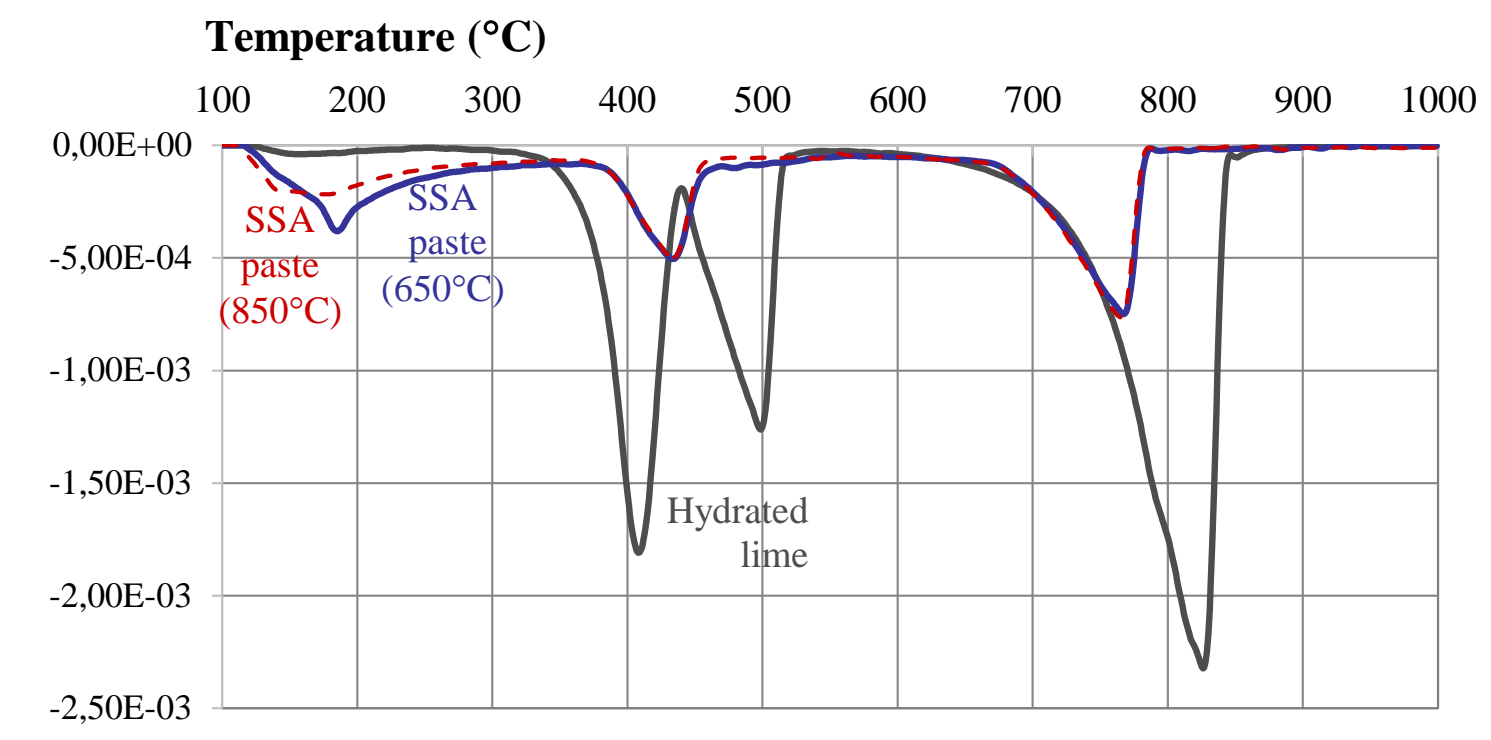

Mass loss rate $\left(\mathbf{m g} /{ }^{\circ} \mathrm{C} / \mathbf{m i n}\right)$

Fig. 11: DTG curves for hydrated lime/SSA calcinated at temperatures of $650^{\circ} \mathrm{C}$ and $850^{\circ} \mathrm{C}$.

Table 4: Values of the temperatures corresponding to the peaks observed in DTG curves

\begin{tabular}{|c|c|c|c|}
\cline { 2 - 4 } \multicolumn{1}{c|}{} & Hydrated lime & SSA $650^{\circ} \mathrm{C}$ paste & SSA $850^{\circ} \mathrm{C}$ paste \\
\hline 1st peak & $409^{\circ} \mathrm{C}$ & $185^{\circ} \mathrm{C}$ & $145^{\circ} \mathrm{C}$ \\
\hline 2nd peak & $499^{\circ} \mathrm{C}$ & $433^{\circ} \mathrm{C}$ & $434^{\circ} \mathrm{C}$ \\
\hline 3rd peak & $827^{\circ} \mathrm{C}$ & $767^{\circ} \mathrm{C}$ & $766^{\circ} \mathrm{C}$ \\
\hline
\end{tabular}

To be considered as a pozzolanic material, according to the Brazilian standard NBR 12653 [7], in one of its requirements, the sum of the oxides $\mathrm{Al}_{2} \mathrm{O}_{3}, \mathrm{SiO}_{2}$ and $\mathrm{Fe}_{2} \mathrm{O}_{3}$ must has a minimum value of $50 \%$ (Class E). The values found for the temperatures of $550^{\circ} \mathrm{C}, 650^{\circ} \mathrm{C}, 750^{\circ} \mathrm{C}$ and $850^{\circ} \mathrm{C}$ were equal to, respectively, $76 \%, 79 \%, 78 \%$ and $81 \%$.

According to the NBR 12653, the content of $\mathrm{SO}_{3}$, for materials of class $\mathrm{E}$, must not exceed $5 \%$. The values found for the temperatures of $550^{\circ} \mathrm{C}, 650^{\circ} \mathrm{C}, 750^{\circ} \mathrm{C}$ and $850^{\circ} \mathrm{C}$ were equal to, respectively, $6.3 \%, 4.5 \%, 3.8 \%$ and $2.6 \%$, so, only when the sample was calcinated at a temperature of $550^{\circ} \mathrm{C}$ is that this limit was exceeded.

It is possible that the presence of $\mathrm{SO}_{3}$, higher than specified limits, may provoke an expansive process, due to the formation of ettringite by reaction with calcium aluminate, when the material is mixed with cement, in order to obtain pastes, mortars or concretes [8].

The content of chlorides obtained for the ashes, at temperatures of $650^{\circ} \mathrm{C}$ e $850^{\circ} \mathrm{C}$ were, respectively, equal to $0.083 \%$ and $0.079 \%$, once the limit for cements is $0.1 \%$. This means that there is not risk of steel rebars corrosion in reinforced concrete.

It was observed that, as the temperature increases, losses of carbon and sulfur occur, and, consequently, an increase of the content of the other components is observed.

The sulfur is probably lost at highest calcining temperatures in form of $\mathrm{SO}_{3}$ or $\mathrm{SO}_{2}$, from sulphates and sulphides present in the material.

X-ray Diffraction tests let to identify the mineralogical composition, by means of sharp peaks, and the presence of the main compounds identified as quartz (silicon dioxide), hematite (iron oxide), anhydrite (calcium sulfate) and goethite (iron oxide). Ash samples presented then a 
crystalline fraction. However, a large noise background was observed (2theta $=20-30^{\circ}$ ) suggesting the presence of amorphous phases.

The following considerations related to Fig. 11 may be done:

a) the hydrated lime has its origin in a dolomitic limestone: the first peak at $409^{\circ} \mathrm{C}$ may be related to the presence of magnesium hydroxide; the second peak, at $499^{\circ} \mathrm{C}$, related to calcium hydroxide; and the third peak, at $827^{\circ} \mathrm{C}$, related to the calcium carbonate;

b) the first peaks for SSA $650^{\circ} \mathrm{C}$ and SSA $850^{\circ} \mathrm{C}$ occurred at temperatures respectively of $185^{\circ} \mathrm{C}$ and $145^{\circ} \mathrm{C}$, and they probably correspond to the elimination of chemically bonded water from the products formed in the pozzolanic reaction; the second and third peaks, probably being due to the dehydroxylation of magnesium hydroxide, at a temperature of $433-434^{\circ} \mathrm{C}$, and the decomposition of calcium carbonate, at a temperature of $766-767^{\circ} \mathrm{C}$, were almost the same for the two pastes;

c) it can be seen that the peak which corresponds to the dehydroxylation of calcium hydroxide, at a temperature of approximately $500^{\circ} \mathrm{C}$, does not exist in the pastes, indicating that there was a pozzolanic reaction between the hydrated lime and the ashes.

\section{Conclusion}

Due to the presented results, it can be concluded that the Sewage Sludge Ash (SSA) used in this work has a potential pozzolanic activity with an adequate limit of chlorides, since the temperature of calcination would be equal or greater than $650^{\circ} \mathrm{C}$.

\section{Acknowledgements}

To CESP Laboratory of Civil Engineering, for the technical support;

To FAPESP, for the undergraduate research grant;

To CAPES, for the post-doctoral grant related to the process BEX 12335/12-6;

To CNPq, for the Research Productivity grant;

To the Sewage Treatment Station at Sao Jose do Rio Preto city (SEMAE), for the technical support;

To the ICITECH, special mention to prof. Mercedes Bonilla and prof. Lourdes Soriano;

To the Institute of Chemistry of Sao Carlos, University of São Paulo (USP), for the technical support;

To prof. Eudes Borges de Araújo and prof. João Carlos Silos Moraes, of the Department of Physics and Chemistry, UNESP - Univ Estadual Paulista, for the technical support.

\section{References}

[1] J. Monzó, J. Payá, M. V. Borrachero, A. Córcoles, Use of sewage sludge ash (SSA)-cement admixtures in mortars, Cement and Concrete Research. Volume 26, Issue 9 (1996) 1389-1398.

[2] A. L. Geyer, Contribuição ao estudo da disposição final e aproveitamento da cinza de lodo de estações de tratamento de esgotos sanitários como adição ao concreto, PhD Thesis, UFRS (2001) $238 \mathrm{p}$.

[3] S. C. Pana, D. H. Tsenga, C. C. Leea, C. Leeb, Influence of the fineness of sewage sludge ash on the mortar, Cement and Concrete Research. Volume 33 (2003) 1749-1754.

[4] E. G. Alcocel, P. Garcés, J. J. Martínez, J. Payá, L. G. Andión, Efecto de la adición de ceniza de lodo de depuradora (CLD) en las propiedades mecánicas y niveles de corrosión de las armaduras embebidas en morteros de cemento Portland, Materiales de Construcción, Vol 56, No 282 (2006) 31-43. 
[5] C. M. A. Fontes, Utilização das cinzas de lodo de esgoto e de resíduo sólido, PhD Thesis, UFRJ (2008) 294p.

[6] J. Payá, P. Garcés, J. Monzó, M. V. Borrachero, L. Soriano, M. Bonilla, A. Mellado, J. M. Saval, L. Reig, New contributions to the Portland cement-sewage sludge ash system, 13th International Conference on the Chemistry of Cement (ICCC), Espanha (2011).

[7] Associação Brasileira de Normas Técnicas - ABNT. NBR 12653: Materiais pozolânicos (1992) 3.p.

[8] J. Monzó, J. Payá, M. V. Borrachero, E. Peris-Mora, Mechanical behavior of mortars containing sewage sludge ash (SSA) and Portland cements with different tricalcium aluminate content, Cement and Concrete Research. Volume 29 (1999) 87-94. 